\title{
ASTASHINE Capsule: A Potential Therapeutic Agent in Removing Body’s Toxins from Internal Organs and Tissues
}

Govind Shukla, Pyaram Manasa, Akanksha Sonal Khess, Sandeep Kunche \& C.J. Sampath Kumar

Pugos Nutrition Research Centre, Hyderabad, India. A Unit of PUGOS Products Pvt. Ltd.,

42, 2nd Floor, Leelavathi Mansion, 6th Cross, Margosa Main Road, Malleshwaram, Bangalore-56003, India.

DOI: http://doi.org/10.38177/AJBSR.2021.3405

Copyright: (๑) 2021 Govind Shukla et al. This is an open access article distributed under the terms of the Creative Commons Attribution License, which permits unrestricted use, distribution, and reproduction in any medium, provided the original author and source are credited.

ASTASHINE capsule contains natural astaxanthin from Haematococcuspluvialis. Astaxanthin has exceptional antioxidant activity to combat single oxygen when compared to other antioxidants. In particular, Astaxanthin can be used to defend against singlet oxygen damage, which is especially susceptible to aging effects. In this study, Astaxanthin extracted from Haematococcus microalgae powerfully quenched singlet oxygen. Results show that the quenching effect of Astaxanthin is 800 times greater than coenzyme Q10. Astaxanthin was also about 75 times greater than alpha lipoic acid, about 550 times greater than green tea catechins and about 6000 times greater than Vitamin C. the present Article reviews the role of ASTASHINE capsule, A Potential Therapeutic Agent in Liver Health and Disease.

Keywords: Astashine capsules, Liver health and Disease.

\section{Introduction}

Astaxanthin (3, 3'-dihydroxy- $\beta, \beta^{\prime}$-carotene-4, 4'-dione, ASX) is a non-vitamin A pro-carotenoid, and has attracted considerable attention from the scientific community due to its antioxidant effect which is 10 times higher than that of $\beta$-carotene and 100 times stronger than that of vitamin E [1]. Astaxanthin exists widely in nature, mainly in the form of fatty acid esters. Numerous studies have shown that astaxanthin has many biological activities, such as antioxidant, anti-aging, and anti-cancer effects, immunity enhancement, free radical scavenging and it plays an active role in human nutrition and health [2]-[4].

\section{Sources of Astaxanthin}

Astaxanthin is produced in two ways: chemical synthesis and biological extraction. Chemical synthesis refers to the preparation of astaxanthin from carotene. Although the synthetic products were cheaper, it is less stable, less absorbable and less safe than natural astaxanthin and has not been legal used in the human diet by the FDA regulation [5]-[7]. Abundant seawater resources produce high-yield marine animals and plants, which provide favorable conditions for the extraction of astaxanthin [8]. On the one hand, astaxanthin can be extracted and recovered from aquatic wastes by enzymatic hydrolysis and the acid-base method, which can not only increase economic benefits, but also reduce environmental pollution, and realize low-carbon and efficient utilization of marine by-products. However, the cost of extraction is high, which is unsuitable for large-scale production.

On the other hand, yeasts including Phaffia rhodozyma, Rhodotorula glutinosa, Rhodotorula cerevisiae and Rhodotorula oceanica produce astaxanthin Colonies of Phaffia rhodozyma are red due to the production of carotenoids such as astaxanthin, and the average content of astaxanthin is $0.40 \%$ [9],[10]. It is noteworthy that many types of marine algae can synthesize astaxanthin, such as snow algae, chlamydia, naked algae, and cyanobacteria. The highest yield was obtained from Haematococcus pluvialis, which can reach 
1.5-3.0\%. The accumulation rate and total production in this species are higher than those in other green algae, and it is recognized as the best biological source of natural astaxanthin [11],[12].

\section{Composition of Astashine capsules}

Astaxanthin - 2 mg

(Naturally derived from Haematococcus pulvialis algae extract, which is microencapsulated).

\section{Structure of Astaxanthin}

The molecular formula of astaxanthin is $\mathrm{C}_{40} \mathrm{H}_{52} \mathrm{O}_{4}$. Its melting point is approximately $224^{\circ} \mathrm{C}$ and it is insoluble in water. Astaxanthin is fat soluble and is soluble in most organic solvents such as chloroform, acetone, ethanol and ether [13]. The chemical structure of astaxanthin is a six-membered ring consisting of four isoprene units linked by conjugated double bonds and two isoprene units at both ends. This double bond structure determines its color and biological function due to its absorptivity. Astaxanthin can produce three optical isomers (3S, 3'S, 3R, 3'S and 3R, $3^{\prime} \mathrm{R}$ ) due to the presence of two chiral carbon atoms ( $\mathrm{R}$ or $\mathrm{S}$ conformations). Natural astaxanthin exists mainly in the form of 3S, 3'S or 3R, 3'R in organisms (Fig.1). In addition, there is a hydroxyl group in the end ring structure, which can form esters with fatty acids; thus, enabling the natural extract of astaxanthin to have stronger antioxidant activity [14].

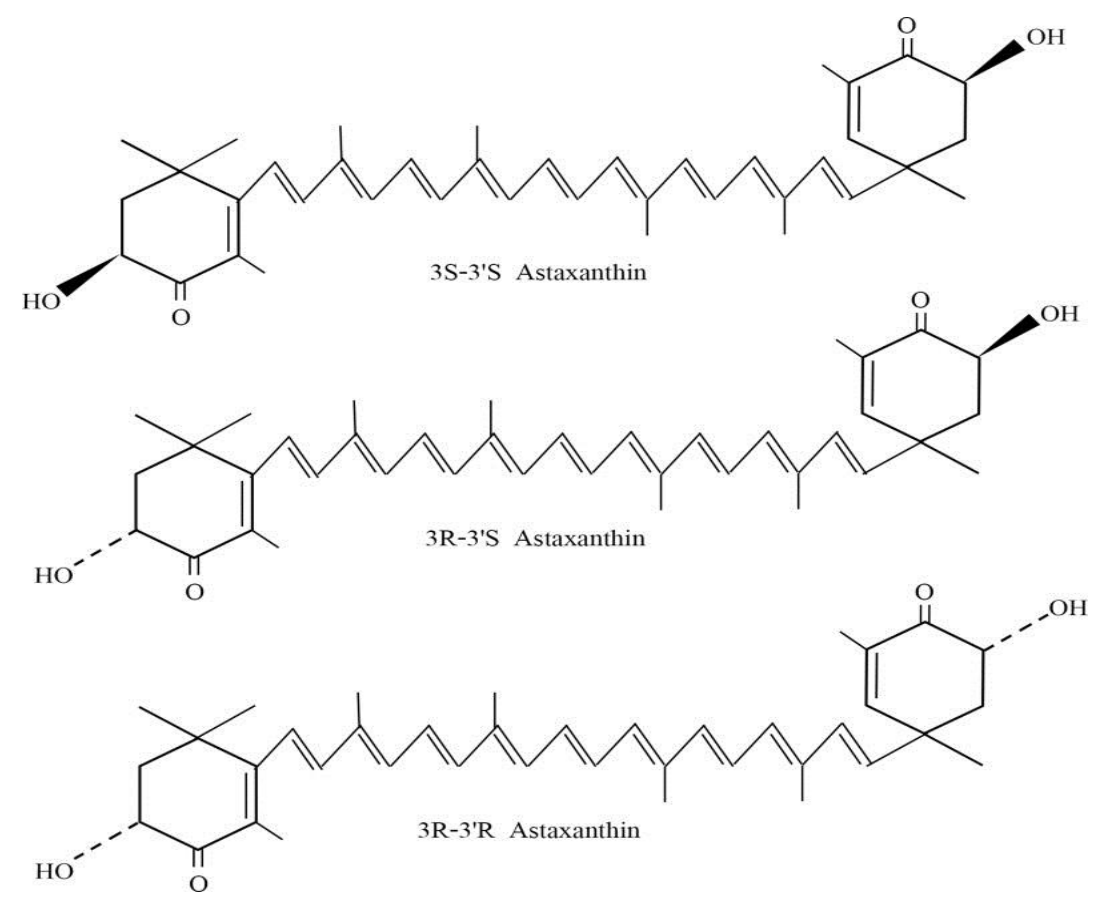

Fig.1. Three stereoisomers of astaxanthin

\section{Biological Safety of Astaxanthin}

Astaxanthin is widely used in various fields due to its many biological activities; thus, its safety is a concern. As early as 1997, astaxanthin was proved to be non-genotoxic [15]. In subsequent studies, Stewart and colleagues confirmed that the highest dose of $6000 \mathrm{mg} / \mathrm{kg} / \mathrm{d}$ did not lead to acute death in rats [16]. Katsumata and Vega found no observed adverse effect for astaxanthin was at least $1000 \mathrm{mg} / \mathrm{kg} / \mathrm{d}$ for 13 weeks in rats [17],[18]. Edwards et al., 
analyzed clinical experimental data, summarized the genetic toxicity of astaxanthin and its carcinogenicity in rats, and showed no carcinogenicity in the rat life cycle [19]. In addition, there are several studies that prove that astaxanthin is liposoluble. Although it can cause pigmentation of animal skin, astaxanthin of over treatment concentration has no adverse effect on platelet, coagulation and fibrinolysis [20],[21].

In 2009, Satoh conducted a safety study of astaxanthin in 127 adults taking $20 \mathrm{mg}$ astaxanthin daily for 4 weeks, and found no organ damage [22]. In addition, different concentrations of astaxanthin also improved the blood lipid level and skin condition of healthy people, but no significant side effects was found [23]-[25]. The above results indicate that astaxanthin is safe with no genetic toxicity or carcinogenicity observed in acute and chronic experiments.

\section{Pharmacokinetics of Astaxanthin}

Whether astaxanthin can exert its biological activity after ingestion depends on its absorption rate, which may be related to its existing form and the level of enzymes in the gastrointestinal tract [26]. Ranga and Parker believe that adding lipid to the diet can improve the bioavailability of astaxanthin [7],[27].

The peak value of astaxanthin in blood taken 30 minutes after a meal is 2.4-3.0 times higher than that taken before a meal, which may be due to stimulation of liver bile secretion and cholesterol lipase after oral administration, which accelerates the hydrolysis and absorption of astaxanthin ester.

Fukami and colleagues synthesized astaxanthin monoester and diester for administration in a rat model. The results showed that the bioavailability of astaxanthin monoester was higher than that of the diester, and the maximum metabolic concentration of astaxanthin monoester in the liver was three times as high as that in serum [28]. The above results show that composition of the fatty acid chain of astaxanthin is closely related to its bioavailability.

\section{Biological Activity of Astaxanthin}

Studies have shown that most carotenes have anti-aging, free radical scavenging, antioxidant and anti-cancer effects, and have been widely used in the fields of medicine, food, cosmetics and feed [1],[29]. Astaxanthin is an effective natural antioxidant and has shown excellent biological functions in many fields of life science [6].

Firstly, astaxanthin is the only carotenoid to penetrate the blood-brain and retinal barriers. It is frequently used as an antioxidant to treat brain injury and cardiovascular diseases, and has been extensively studied in clinical practice [4],[30]. In addition, astaxanthin has shown anti-cancer effects in many cancers, including liver cancer, colon cancer, bladder cancer, oral cancer and leukemia [3],[31]-[33].

In addition, many animal experiments have proved that astaxanthin plays an important role in regulating sugar metabolism, improving immunity and improving motor function [5] (Fig.2).

As the largest digestive gland in the human body, the liver not only undertakes the metabolism and transformation of nutrients in the body, but also participates in the defense and immunity of the body, coagulation factor synthesis and other physiological processes. The effects and mechanisms of astaxanthin on liver diseases, such as non-alcoholic fatty liver disease (NAFLD), liver fibrosis, hepatitis and hepatocellular carcinoma, are summarized. 


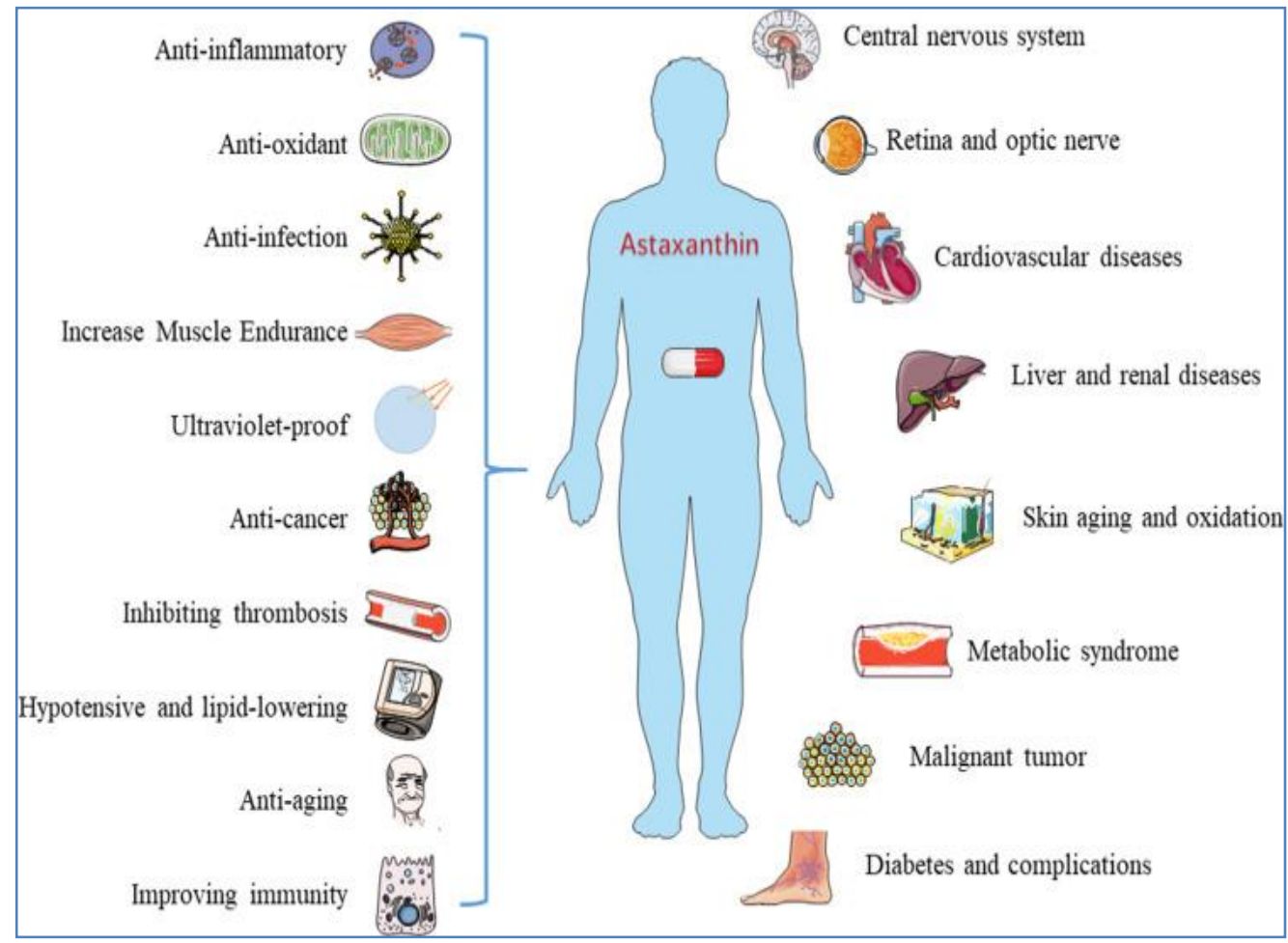

Fig.2. Biological activity of astaxanthin and its function in relevant diseases

\section{The Role of Astaxanthin in Liver Diseases}

Astaxanthin has been used in the prevention and treatment of a variety of systemic diseases in vivo due to its various biological activities. In recent years, researchers have confirmed that astaxanthin plays an important role in preventing acute liver injury, alleviating insulin resistance and NAFLD, liver fibrosis and liver cancer [34].

\section{Liver Fibrosis}

Liver fibrosis is a key link in the deterioration of chronic liver diseases such as viral hepatitis and fatty liver. Without effective intervention, $75-80 \%$ of these diseases can develop into cirrhosis, which seriously endangers human health [35],[36]. The synthesis of extracellular matrix (ECM) induced by activation of hepatic stellate cells (HSCs) and the transformation of myofibroblasts (MFs) are the key factors in hepatic fibrosis. The reversibility of these factors also provides an important research target for the reversal of hepatic fibrosis. The mechanism of liver fibrosis is complex, involving the regulation of histopathology, cytology, cytokines and their molecular levels [37]. Studies have confirmed that astaxanthin plays an anti-fibrotic role via its antioxidant, apoptotic, lipid peroxidation and autophagy activities.

Yang et al demonstrated that astaxanthin inhibited the activation of resting HSCs and restored the resting state of activated HSCs in mice. Astaxanthin also decreased reactive oxygen species (ROS) production and increased the expression of nuclear factor erythroid 2-related factor $2(\mathrm{NrF} 2)$, the main transcription factor in endogenous antioxidant defense [38]. Therefore, the protective effect of astaxanthin on hepatic fibrosis may be attributed to its enhanced antioxidant capacity. Islam and colleagues subsequently demonstrated that astaxanthin could restore the activity of catalase (CAT) and superoxide dismutase (SOD) in rats with carbon tetrachloride (CCl4)-induced liver 
fibrosis, and prevent liver fibrosis induced by CCL4 by inhibiting lipid peroxidation and stimulating the cell antioxidant system [39].

The transforming growth factor (TGF)- $\beta$ /Smads pathway is a key pathway in the induction of ECM formation during hepatic fibrosis. Astaxanthin has been shown to inhibit ECM formation through the TGF- $\beta 1 / \mathrm{Smad} 3$ pathway in the human HSC cell line LX-2 [40]. There are many downstream influencing factors, and apoptosis and autophagy are two programmed cell death pathways directly related to the survival status of HSCs in hepatic fibrosis. On the one hand, astaxanthin can induce apoptosis of LX-2 cells by regulating mir-29b, which mainly inhibits Bcl-2 and increases the expression levels of Bax and Caspase-3, thus playing a role in preventing liver fibrosis [41]. On the other hand, astaxanthin significantly improved liver fibrosis induced by CCL4 and bile duct ligation (BDL) in mice. It can also reduce the expression of TGF- $\beta 1$ and autophagy by inhibiting the level of nuclear factor (NF)- $\mathrm{kB}$, which inhibits the activation of HSCs and the formation of ECM [42]. Its effectiveness is related to the release of energy by autophagy through lipid droplet degradation, thus providing favorable conditions for the activation of HSCs [43]. In addition, histone acetylation, as an epigenetic model, participates in the activation of HSCs and liver fibrosis [44]. The level of histone deacetylase 9 (HDAC9) in primary biliary cirrhosis of the liver was significantly higher than that in normal liver, and other liver pathologies showed high expression of HDAC9. Accordingly, Yang et al found that the level of HDAC9 in primary activated HSCs increased significantly, while HDAC9 knockout in LX-2 cells decreased the expression of the fibrosis gene induced by TGF- $\beta 1$. It was proved that astaxanthin significantly inhibited the activation of HSCs by down-regulating the expression of HDAC9. HDAC3 and HDAC4 may also participate in the inhibition of HSCs activation by astaxanthin [45].

\section{Non-Alcoholic Fatty Liver Disease}

Non-alcoholic fatty liver disease (NAFLD) refers to a clinicopathological syndrome characterized by excessive fat deposition in hepatocytes, excluding alcohol and other specific liver-damaging factors, and mainly includes non-alcoholic steatohepatitis (NASH). NAFLD is an important metabolic syndrome, which can increase mortality in obese and diabetic patients [48]. At present, the pathogenesis of NAFLD is complex, and is related to many factors, such as insulin resistance, oxidative stress, inflammatory mediators and cytokines. At present, there are no effective targeted drugs for the treatment of NAFLD, and treatment includes diet therapy and lifestyle adjustment, liver protection and lipid lowering, and insulin sensitization [49],[50]. Astaxanthin has a wide range of effects, and may play an effective role in preventing the pathogenesis of NAFLD from many aspects.

In 2007, Ikeuchi et al., studied the effect of astaxanthin supplementation on obese mice fed a high fat diet. The results showed that astaxanthin inhibited the increase in body weight and adipose tissue caused by the high fat diet. In addition, astaxanthin also reduced liver weight and liver triglyceride, plasma triglyceride and total cholesterol levels [51]. These results indicate that astaxanthin may play an important role in improving lipid metabolism and lays the foundation for future research on the treatment of NAFLD.

The release of inflammatory factors is crucial in the pathogenesis of NAFLD. Ni et al., found that astaxanthin significantly reduced M1 macrophages and increased M2 macrophages, reduced liver recruitment of $\mathrm{CD}^{+}$and 
$\mathrm{CD}^{+}$and inhibited inflammation in NAFLD. Compared with vitamin E, astaxanthin reduced lipid accumulation, improved insulin signal transduction and inhibited pro-inflammatory signal transduction more effectively by inhibiting the activation of Jun N-terminal kinase (JNK)/p38 mitogen-activated protein kinase (MAPK) and NF- $\mathrm{kB}$ pathways [52]. Similarly, Kim demonstrated that astaxanthin reduced macrophage infiltration and the expression of macrophage markers in mice, inhibited inflammation and fibrosis in liver and adipose tissue, and enhanced the ability of skeletal muscle to oxidize mitochondrial fatty acids in obese mice [53].

Peroxisome proliferator-activated receptors (PPARs) play an important role in the regulation of inflammation. Activated PPAR- $\alpha$ has become a key target in NAFLD as it can improve fatty acid transport, metabolism, oxidation and inhibit liver fat accumulation. In addition, activation of PPAR- $\gamma$ can also regulate gene expression related to lipid synthesis and promote fatty acid storage [54],[55]. Overexpression of PPAR- $\gamma$ can induce lipid accumulation in the liver.

Kobori et al., used DNA microarray to analyze gene expression in the liver of mice fed astaxanthin. It was found that astaxanthin inhibited PPARs. Screening drugs for liver PPARs and their related molecular functions in mice provided a new therapeutic basis for NAFLD [56].

Jia et al., confirmed the above findings in animal models. Astaxanthin was administered orally to mice fed a high-fat diet for 8 weeks. It was found that astaxanthin improved liver lipid accumulation induced by a high-fat diet, reduced triglyceride levels in the liver, and decreased the number of inflammatory macrophages and Kupffer cells. These changes were attributed to the regulation of PPARs by astaxanthin. Astaxanthin activates PPAR- $\alpha$ and inhibits the expression of PPAR- $\gamma$ and the levels of interleukin- 6 and tumor necrosis factor- $\alpha$ in the liver, inhibits inflammation and reduces fat synthesis in the liver. In addition, astaxanthin also causes autophagy of hepatocytes by inhibiting the AKT-mTOR pathway and decomposes lipid droplets stored in the liver [57]. Compared with N-Acetyl-L-cysteine (NAC) and vitamin C (VC), astaxanthin effectively reduced intracellular lipid deposition [58].

In addition, astaxanthin also significantly inhibited the expression of fatty acid synthase and acetyl coenzyme A carboxylase, increased SOD, CAT, GPX activity and glutathione (GSH) in the liver, and significantly reduced lipid peroxidation in the liver [59]. Yang et al., demonstrated that astaxanthin significantly reduced the accumulation of TAG in apolipoprotein E knockout mice, and increased the expression of $\mathrm{NrF} 2$ and its target genes (including SOD 1 and glutathione peroxidase 1). This is very important for the endogenous antioxidant mechanism [60], [61]. Compared with the standard NAFLD antioxidant vitamin E, astaxanthin not only inhibits the expression of lipid-producing genes but also improves the level of liver enzymes; vitamin E only reduces blood lipids.

In clinical trials, a prospective, randomized, double-blind study confirmed the effect of astaxanthin on oxidative stress in overweight and obese adults in Korea. Twenty-three adults with a body mass index $>25.0 \mathrm{~kg} / \mathrm{m}^{2}$ were enrolled in this study and randomly divided into two dosage groups: astaxanthin $5 \mathrm{mg}$ or $20 \mathrm{mg}$ once a day for 3 weeks. The results showed that the oxidative stress markers, malondialdehyde (MDA), isoprostane (ISP), SOD and total antioxidant capacity (TAC) were significantly improved [62]. In view of these beneficial effects, astaxanthin should be further evaluated as a new and promising treatment for NAFLD. 


\section{Liver Cancer}

Hepatocellular carcinoma (HCC) accounts for 70-90\% of primary liver cancer, and the complex pathogenesis and genetic polymorphisms restrict the development of HCC therapy and seriously endanger human health. In recent years, although progress has been made in clinical research of HCC, the mechanism of invasion and metastasis is still not fully clear. The development of HCC is closely related to many signaling pathways, such as MAPK, PI3K/Akt/mTOR, JAK/STAT, Wnt/B-catenin, NrF2/ARE and VEGF [63],[64]. Astaxanthin has been shown to play an important role in cancer prevention, inhibition of cell proliferation and metastasis, promotion of cell apoptosis and enhancement of immunity [3].

As early as the 1990s, Gradelet et al discovered that astaxanthin inhibited the occurrence and development of HCC by inhibiting the binding of aflatoxin B1 (AFB1) to liver DNA and plasma albumin in the AFB1-induced hepatoma model [65]. In 2010, Tripathi confirmed that astaxanthin reduced the number and area of liver cancer lesions in rats by regulating the NrF2/ARE pathway in early cyclophosphamide-induced liver tumors, and played an important role in preventing the occurrence and development of liver cancer [66]. Song and Li proved that astaxanthin promoted mitochondrial apoptosis of CBRH-7919 mouse hepatoma cells and human LM3 and SMMC-7721 hepatoma cells in a concentration-dependent manner. The mechanism was related to JAK1/STAT3, NF-кB P65 and Wnt/ $\beta$-catenin. In addition, astaxanthin may also regulate nucleoside diphosphate kinase (NPK) nm-23, which is conducive for the correct assembly of cytoskeleton and signal transfer of T protein, thus inhibiting the occurrence of liver tumors [33],[67],[68]. Consistent with the above results, Shao et al demonstrated that astaxanthin inhibited cell proliferation and promoted cell apoptosis in vitro and in vivo, and that astaxanthin mainly blocked the cell cycle in G2 phase [69]. Abnormal lipid metabolism is an important feature in the occurrence and development of malignant tumors and obesity is more likely to cause tumors. Fatty acid synthase, which regulates lipid metabolism, has been demonstrated to be elevated in a variety of cancer models [70]. Ohno et al., studied the fatty acid synthase (FASN) regulation of astaxanthin in a mouse model. It was found that astaxanthin improved the level of serum adiponectin and significantly reduced reactive oxygen metabolites/biological antioxidant potential ratio, thus playing a role in liver tumors of obese individuals [71].

As mentioned above, animal experiments have demonstrated the preventive and therapeutic effects of astaxanthin on many types of tumors, and its mechanism has been investigated. It has been found that astaxanthin may be related to a variety of signaling pathways, but its specific mechanism is still unclear and requires further study.

\section{Alcoholic Liver Disease}

Liver is the main organ in drug metabolism, and some drugs are metabolized only in hepatocytes. Therefore, the intake of toxic substances can easily lead to accumulation and damage of hepatocytes. Alcoholic hepatitis is mainly caused by direct or indirect inflammation, oxidative stress, enterogenous endotoxin, inflammatory mediators and nutritional imbalance during the metabolism of ethanol and its derivatives [72],[73]. Studies have shown that astaxanthin can alleviate liver steatosis and inflammation caused by ethanol [74]. In addition, the levels of ROS, pro-inflammatory proteins and related inflammatory factors were also significantly decreased in liver tissue in the drug group, which may be related to negative phosphorylation of STAT3 [75]. Besides inhibiting oxidative stress 
and inflammation to prevent alcohol-induced liver damage, astaxanthin can also regulate intestinal flora and may play a potential therapeutic role in alcoholic liver disease-induced bacterial diseases [76]. Similarly, liposomal encapsulation of astaxanthin exerted rapid and direct effects against repeated alcohol-induced liver disease and could boost recovery from liver injuries caused by long-term alcohol intake [77].

\section{Drug-Induced Liver Injury}

Astaxanthin has also been shown to be effective in other drug-induced liver injury. Turkez demonstrated in cell and animal models that astaxanthin significantly reduced liver injury induced by 2,3,7,8-tetrachlorodibenzo-p-dioxin (TCDD) and significantly increased the activity of inhibited antioxidant enzymes [78],[79]. In addition, by inhibiting the expression of inflammatory factors such as TNF- $\alpha$ and ROS production, liver injury induced by paracetamol (APAP), concanavalin A (ConA) and lipopolysaccharide (LPS) can be alleviated. The main mechanism of this effect may be related to inhibition of the MAPK family and NF- $\mathrm{B}$ pathways [47],[80], [81]. Therefore, astaxanthin not only effectively inhibits the occurrence and development of liver fibrosis, NAFLD and liver cancer, but also plays an important role in the prevention of acute drug-induced injury.

\section{Hepatic Ischemia-Reperfusion}

Hepatic ischemia-reperfusion (IR) injury often occurs after hepatectomy, liver transplantation and shock, and can cause serious liver dysfunction [82]. With improvements in economic and living conditions, more patients with end-stage liver disease choose liver transplantation to prolong their lives. Therefore, it is essential to prevent liver IR injury. At present, it is generally believed that such injuries are related to ROS, Kupffer cells, inflammatory cytokines, and ROS are key to inducing such injuries [83],[84]. Astaxanthin, a strong antioxidant, has been shown to play an important role in IR of the cardiovascular system, liver and kidney [84]-[87]. Curek and colleagues first demonstrated that after 14 days of astaxanthin preconditioning, hepatocyte injury and mitochondrial swelling were lower in IR rats and unprotected groups, and it was shown that astaxanthin significantly inhibited the conversion of xanthine dehydrogenase $(\mathrm{XDH})$ to xanthine oxidase (XO) [88]. This suggests that astaxanthin improves hepatic IR injury via its antioxidant effect. Li et al., subsequently determined ROS and inflammatory factors in a mouse model of IR after astaxanthin preconditioning to determine the role of astaxanthin in scavenging oxidative stress products, and examined the relevant mechanisms, which may be related to down-regulation of the activity of the MAPK family-related proteins, thus inhibiting apoptosis and autophagy [89]. In addition, the apoptosis of hepatocytes induced by hypoxia can also be inhibited by astaxanthin, which further demonstrates that astaxanthin has a protective effect in hepatic IR injury via antioxidation, and is a safe and effective treatment method [90]. The role of astaxanthin in liver disease is summarized in Table 1.

Table 1. Summary of Astaxanthin in Liver Diseases

\begin{tabular}{|c|c|c|c|c|c|}
\hline Diseases & Model & Dosage & Duration & Effects & References \\
\hline \multirow{2}{*}{ Liver Fibrosis } & Primary HSCs & $25 \mu \mathrm{M}$ & $2-4 \mathrm{~d}$ & Anti-oxidation & {$[33]$} \\
\cline { 2 - 6 } & Rats & $10 \mathrm{mg} / \mathrm{kg}$ & $2 \mathrm{w}$ & Anti-oxidation & {$[34]$} \\
\hline
\end{tabular}


Volume 3, Issue 4, Pages 36-52, October-December 2021

\begin{tabular}{|c|c|c|c|c|c|}
\hline Diseases & Model & Dosage & Duration & Effects & References \\
\hline & $\begin{array}{c}\text { Primary HSCs } \\
\text { LX-2 cells }\end{array}$ & $25 \mu \mathrm{M}$ & $12 \mathrm{~h} 24 \mathrm{~h}$ & $\begin{array}{l}\text { TGF- } \beta / \text { Smads } \\
\text { ECM formation }\end{array}$ & {$[35]$} \\
\hline & LX-2 cells & $10-40 \mu \mathrm{M}$ & $24 \mathrm{~h} 48 \mathrm{~h}$ & Pro-Apoptosis & {$[36]$} \\
\hline & Mice & $\begin{array}{l}20-80 \\
\mathrm{mg} / \mathrm{kg}\end{array}$ & $8 w$ & $\begin{array}{c}\text { TGF- } \beta / \text { Smads } \\
\text { Autophagy }\end{array}$ & {$[37]$} \\
\hline & $\begin{array}{c}\text { Primary HSCs } \\
\text { LX-2 cells }\end{array}$ & $25 \mu \mathrm{M}$ & $24 \mathrm{~h}$ & $\begin{array}{c}\text { TGF } \beta 1 / \text { Smads } \\
\text { HDAC9 }\end{array}$ & [40] \\
\hline \multirow{7}{*}{ NAFLD } & $\begin{array}{c}\text { Mice } \\
\text { Primary } \\
\text { hepatocytes }\end{array}$ & $\begin{array}{c}0.02 \% \\
25-100 \mu \mathrm{M}\end{array}$ & $\begin{array}{l}10 \mathrm{w} \\
16 \mathrm{~h}\end{array}$ & Anti-inflammatory & {$[46]$} \\
\hline & Mice & $0.03 \%$ & $15-30 \mathrm{w}$ & Anti-inflammatory & [47] \\
\hline & $\begin{array}{c}\text { HepG2 HEK293 } \\
\text { Mice }\end{array}$ & $\begin{array}{l}6-30 \mu \mathrm{M} \\
30 \mathrm{mg} / \mathrm{kg}\end{array}$ & $\begin{array}{l}12 \mathrm{~h} \\
8 \mathrm{w}\end{array}$ & Anti-inflammatory & [51] \\
\hline & HepG2 cells & $10 \mu \mathrm{M}$ & $24 \mathrm{~h}$ & Anti-inflammatory & {$[52]$} \\
\hline & Rats & $1 \mathrm{~g} / \mathrm{kg}$ & $10 \mathrm{w}$ & Anti-oxidation & {$[53]$} \\
\hline & Mice & $0.03 \%$ & $12 \mathrm{w}$ & Anti-oxidation & {$[54],[55]$} \\
\hline & Adults & $5-20 \mathrm{mg}$ & $3 w$ & Anti-oxidation & {$[56]$} \\
\hline \multirow{6}{*}{ Liver Cancer } & AFB1-Rats & $300 \mathrm{ppm}$ & $5 \mathrm{~d}$ & DNA & [59] \\
\hline & CTX-Rats & $25 \mathrm{mg} / \mathrm{kg}$ & $2 \mathrm{w}$ & $\mathrm{NrF} 2$ & {$[60]$} \\
\hline & CBRH-7919 & $0-100 \mu \mathrm{M}$ & $24 \mathrm{~h}$ & JAK1/STAT3 & {$[61],[62]$} \\
\hline & $\begin{array}{c}\text { LM3 } \\
\text { SMMC-7721 }\end{array}$ & $0-200 \mu \mathrm{M}$ & $0-72 \mathrm{~h}$ & $\begin{array}{c}\text { NF-кB P65 } \\
\text { Wnt//-Catenin }\end{array}$ & [27] \\
\hline & $\begin{array}{l}\mathrm{H} 22 \\
\text { Mice }\end{array}$ & $\begin{array}{l}20-40 \mu \mathrm{M} \\
2-4 \mu \mathrm{g} / \mathrm{kg}\end{array}$ & $\begin{array}{c}12-24 \mathrm{~h} \\
7 \mathrm{~d}\end{array}$ & $\begin{array}{c}\text { Apoptosis } \\
\text { Arrest in G2 phase }\end{array}$ & [63] \\
\hline & DEN-Mice & 200 ppm & $20 \mathrm{w}$ & FASN & {$[65]$} \\
\hline \multirow{3}{*}{$\begin{array}{l}\text { Drug-Induced } \\
\text { Liver Injury }\end{array}$} & Alcoholic-mice & $50 \mathrm{mg} / \mathrm{kg}$ & $10 \mathrm{w}$ & $\begin{array}{l}\text { Anti-inflammatory } \\
\text { MAPK }\end{array}$ & [68] \\
\hline & Alcoholic-mice & $\begin{array}{c}0.2- \\
20 \mathrm{mg} / \mathrm{kg}\end{array}$ & $10 \mathrm{~d}$ & $\begin{array}{l}\text { Anti-inflammatory } \\
\text { Anti-oxidation }\end{array}$ & [69] \\
\hline & Alcoholic-mice & $50 \mathrm{mg} / \mathrm{kg}$ & $12 \mathrm{w}$ & Anti-inflammatory Regulation & {$[70]$} \\
\hline
\end{tabular}


Asian Journal of Basic Science \& Research

Volume 3, Issue 4, Pages 36-52, October-December 2021

\begin{tabular}{|c|c|c|c|c|c|}
\hline Diseases & Model & Dosage & Duration & Effects & References \\
\hline & & & & of intestinal flora & \\
\hline & APAP-mice & $\begin{array}{l}30-60 \\
\mathrm{mg} / \mathrm{kg}\end{array}$ & $14 \mathrm{~d}$ & $\begin{array}{c}\text { Anti-inflammatory } \\
\text { Anti-oxidation }\end{array}$ & {$[75]$} \\
\hline & ConA-mice & $\begin{array}{l}20-40 \\
\mathrm{mg} / \mathrm{kg}\end{array}$ & $14 \mathrm{~d}$ & $\begin{array}{c}\text { Anti-inflammatory } \\
\text { JNK }\end{array}$ & [74] \\
\hline & $\begin{array}{l}\text { TCDD-Rats } \\
\text { hepatocytes }\end{array}$ & $\begin{array}{c}12.5-25 \\
\mathrm{mg} / \mathrm{kg} \\
2.5-10 \mu \mathrm{M}\end{array}$ & $\begin{array}{l}21 \mathrm{~d} \\
48 \mathrm{~h}\end{array}$ & Anti-oxidation & {$[71],[72]$} \\
\hline & LPS-mice & $2-10 \mathrm{mg} / \mathrm{kg}$ & $7 \mathrm{~d}$ & $\begin{array}{c}\text { Anti-inflammatory } \\
\text { Anti-oxidation }\end{array}$ & [73] \\
\hline \multirow{3}{*}{ Liver IR } & Rats & $5 \mathrm{mg} / \mathrm{kg}$ & $14 \mathrm{~d}$ & Anti-oxidation & {$[82]$} \\
\hline & Mice & $\begin{array}{l}30-60 \\
\mathrm{mg} / \mathrm{kg}\end{array}$ & $14 \mathrm{~d}$ & Anti-oxidation & [83] \\
\hline & Mice & $\begin{array}{c}25 \mathrm{mg} / \mathrm{kg} \\
10 \mu \mathrm{M}\end{array}$ & $\begin{array}{c}0-48 \mathrm{~h} \\
24 \mathrm{~h}\end{array}$ & Anti-oxidation & [84] \\
\hline
\end{tabular}

Abbreviations: DEN, diethylnitrosamine; CTX, cyclophosphamide; APAP, acetaminophen; ConA, concanavalin A; LPS, lipopolysaccharide; AFB1, aflatoxin B1; TCDD, 2,3,7,8-tetrachlorodibenzo-p-dioxin.

\section{Safety of Astashine Capsules}

Astaxanthin has demonstrated safety in numerous human clinical trials. In one open-label clinical study on subjects with metabolic syndrome $(\mathrm{n}=17)$.Astaxanthin ( $16 \mathrm{mg} /$ day, for three months) significantly raised blood bilirubin $(\mathrm{p} \leq 0.05)$, potassium $(\mathrm{p} \leq 0.05)$, and creatinekinase $(\mathrm{p} \leq 0.01)$, although all three values remained within normal range.

Also, astaxanthin significantly lowered the liver enzyme gamma-glutamyltranspeptidase (GGTP; $p \leq 0.05$ ). Since the researchers noted this enzyme was abnormally elevated in 11 of the 17 subjects at baseline, this astaxanthin effect may have been beneficial.

Animal experiments have investigated astaxanthin at levels well over $120 \mathrm{mg} /$ day in human equivalents, without causing apparent harm. Hoffman-La Roche confirmed its safety with extensive tests, including acute toxicity, mutagenicity, teratogenicity, embryotoxicity, and reproductive toxicity.

\section{Suggested Dosage}

The doses of astaxanthin used in clinical trials have ranged from $1 \mathrm{mg} /$ day to $40 \mathrm{mg} / \mathrm{day}$ (with the majority in the 6-12 mg range); single-dose pharmacokinetic studies used up to $100 \mathrm{mg}$ per dose. As a dietary supplement, astaxanthin should be taken along with fats, with or immediately prior to meals, to ensure its optimal absorption. 


\section{Conclusion and Perspectives}

Astaxanthin is a secondary carotenoid mainly obtained from marine organisms. Studies have shown that astaxanthin has preventive and therapeutic effects on liver fibrosis, liver tumors, liver ischemia-reperfusion injury, non-alcoholic fatty liver and other related diseases. Astaxanthin not only has strong antioxidant effect, but also can regulate many signal pathways. For example, it reduces JNK and ERK-1 activity to improve liver insulin resistance, inhibits PPAR- $\gamma$ expression to reduce fat synthesis in the liver, down-regulates the expression of TGF- $\beta 1 /$ Smad3 to inhibit the activation of HSCs and liver fibrosis, inhibits the JAK/STAT3 and Wnt/ $\beta$-catenin signaling pathways to inhibit liver tumors, and inhibits apoptosis and autophagy to protect against liver ischemia-reperfusion injury.

The role of astaxanthin in liver diseases and its related mechanisms were summarized in this study. Astaxanthin can prevent and treat liver diseases by inhibiting inflammation and improving glycolipid metabolism [91]. Therefore, astaxanthin could have widespread application in the prevention and treatment of liver diseases.

\section{Declarations}

\section{Source of Funding}

This research did not receive any grant from funding agencies in the public, commercial, or not-for-profit sectors.

\section{Competing Interests Statement}

The authors declare no competing financial, professional and personal interests.

\section{Consent for publication}

Authors declare that they consented for the publication of this research work.

\section{References}

1. Henriquez V, Escobar C, Galarza J, Gimpel J. Carotenoids in Microalgae. Subcell Biochem. 2016; 79: $219-237$.

2. Fassett RG, Coombes JS. Astaxanthin in cardiovascular health and disease. Molecules.2012; 17(2): 2030-2048. doi:10.3390/molecules 17022030.

3. Zhang L, Wang H. Multiple mechanisms of anti-cancer effects exerted by astaxanthin. Mar Drugs. 2015; 13(7): $4310-4330$.

4. Fassett RG, Coombes JS. Astaxanthin: a potential therapeutic agent in cardiovascular disease. Mar Drugs. 2011; 9(3): 447-465.

5. Brown DR, Gough LA, Deb SK, Sparks SA, McNaughton LR. Astaxanthin in exercise metabolism, performance and recovery: a review. Front Nutr. 2017; 4:76.

6. Fakhri S, Abbaszadeh F, Dargahi L, Jorjani M. Astaxanthin: a mechanistic review on its biological activities and health benefits. Pharmacol Res. 2018; 136: 1-20. 
Asian Journal of Basic Science \& Research Volume 3, Issue 4, Pages 36-52, October-December 2021

7. Parker RS. Absorption, metabolism, and transport of carotenoids. FASEB J. 1996; 10(5): 542-551.

8. Ambati RR, Phang SM, Ravi S, Aswathanarayana RG. Astaxanthin: sources, extraction, stability, biological activities and its commercial applications-a review. Mar Drugs. 2014; 12(1): 128-152.

9. Molino A, Mehariya S, Iovine A, et al. Extraction of astaxanthin and lutein from microalga haematococcus pluvialis in the red phase using $\mathrm{CO}(2)$ supercritical fluid extraction technology with ethanol as co-solvent. Mar Drugs. 2018; 16(11).

10. Hong ME, Choi HI, Kwak HS, et al. Rapid selection of astaxanthin-hyperproducing Haematococcus mutant via azide-based colorimetric assay combined with oil-based astaxanthin extraction. Bioresour Technol. 2018; 267: $175-181$.

11. Rammuni MN, Ariyadasa TU, Nimarshana PHV, Attalage RA. Comparative assessment on the extraction of carotenoids from microalgal sources: astaxanthin from $\mathrm{H}$. pluvialis and beta-carotene from D. salina. Food Chem. 2019; 277: 128-134.

12. Peng J, Yuan JP, Wang JH. Effect of diets supplemented with different sources of astaxanthin on the gonad of the sea urchin anthocidaris crassispina. Nutrients. 2012; 4(8): 922-934.

13. Misawa N, Satomi Y, Kondo K, et al. Structure and functional analysis of a marine bacterial carotenoid biosynthesis gene cluster and astaxanthin biosynthetic pathway proposed at the gene level. J Bacteriol. 1995; 177(22): 6575-6584.

14. Pan L, Wang H, Gu K. Nanoliposomes as vehicles for astaxanthin: characterization, in vitro release evaluation and structure. Molecules. 2018; 23 (11): 2822.

15. Astorg P, Gradelet S, Leclerc J, Siess MH. Effects of provitamin A or non-provitamin A carotenoids on liver xenobiotic-metabolizing enzymes in mice. Nutr Cancer. 1997; 27(3): 245-249.

16. Stewart JS, Lignell A, Pettersson A, Elfving E, Soni MG. Safety assessment of astaxanthin-rich microalgae biomass: acute and subchronic toxicity studies in rats. Food Chem Toxicol. 2008; 46(9): 3030-3036.

17. Katsumata T, Ishibashi T, Kyle D. A sub-chronic toxicity evaluation of a natural astaxanthin-rich carotenoid extract of Paracoccus carotinifaciens in rats. Toxicol Rep. 2014; 1: 582-588.

18. Vega K, Edwards J, Beilstein P. Subchronic (13-week) toxicity and prenatal developmental toxicity studies of dietary astaxanthin in rats. Regul Toxicol Pharmacol. 2015; 73(3): 819-828.

19. Edwards JA, Bellion P, Beilstein P, Rumbeli R, Schierle J. Review of genotoxicity and rat carcinogenicity investigations with astaxanthin. Regul Toxicol Pharmacol. 2016; 75: 5-19.

20. Serebruany V, Malinin A, Goodin T, Pashkow F. The in vitro effects of Xancor, a synthetic astaxanthine derivative, on hemostatic biomarkers in aspirin-naive and aspirin-treated subjects with multiple risk factors for vascular disease. Am J Ther. 2010; 17(2): 125-137. 
Asian Journal of Basic Science \& Research

Volume 3, Issue 4, Pages 36-52, October-December 2021

21. Rao AR, Sindhuja HN, Dharmesh SM, Sankar KU, Sarada R, Ravishankar GA. Effective inhibition of skin cancer, tyrosinase, and antioxidative properties by astaxanthin and astaxanthin esters from the green alga Haematococcus pluvialis. J Agric Food Chem. 2013 ;61(16): 3842-3851.

22. Satoh A, Tsuji S, Okada Y, et al. Preliminary clinical evaluation of toxicity and efficacy of A new astaxanthin-rich haematococcus pluvialis extract. J Clin Biochem Nutr. 2009; 44(3): 280-284.

23. Tominaga K, Hongo N, Karato M, Yamashita E. Cosmetic benefits of astaxanthin on humans subjects. Acta Biochim Pol. 2012; 59(1): 43-47.

24. Karppi J, Rissanen TH, Nyyssonen K, et al. Effects of astaxanthin supplementation on lipid peroxidation. Int J Vitam Nutr Res. 2007; 77(1): 3-11.

25. Osterlie M, Bjerkeng B, Liaaen-Jensen S. Plasma appearance and distribution of astaxanthin E/Z and R/S isomers in plasma lipoproteins of men after single dose administration of astaxanthin. $J$ Nutr Biochem. 2000; 11(10): 482-490.

26. Failla ML, Chitchumronchokchai C, Ferruzzi MG, Goltz SR, Campbell WW. Unsaturated fatty acids promote bioaccessibility and basolateral secretion of carotenoids and alpha-tocopherol by Caco-2 cells. Food Funct. 2014; 5(6): 1101-1112.

27. Ranga Rao A, Raghunath Reddy RL, Baskaran V, Sarada R, Ravishankar GA. Characterization of microalgal carotenoids by mass spectrometry and their bioavailability and antioxidant properties elucidated in rat model. $J$ Agric Food Chem. 2010; 58(15): 8553-8559.

28. Harukazu Fukami KN, Sugiura-Tomimori N, Sumida M, Katano K, Nakao M. Chemical synthesis of astaxanthin n-octanoic acid monoester and diester and evaluation of their oral absorbability. J Oleo Sci. 2006; 55(12): 653-656.

29. Zuluaga M, Gueguen V, Pavon-Djavid G, Letourneur D. Carotenoids from microalgae to block oxidative stress. Bioimpacts. 2017; 7(1): 1-3.

30. Grimmig B, Kim SH, Nash K, Bickford PC, Douglas Shytle R. Neuroprotective mechanisms of astaxanthin: a potential therapeutic role in preserving cognitive function in age and neurodegeneration. Geroscience. 2017; 39(1).

31. Kowshik J, Baba AB, Giri H, Deepak Reddy G, Dixit M, Nagini S. Astaxanthin inhibits JAK/STAT-3 signaling to abrogate cell proliferation, invasion and angiogenesis in a hamster model of oral cancer. PLoS One. 2014; 9(10).

32. Kavitha K, Kowshik J, Kishore TK, Baba AB, Nagini S. Astaxanthin inhibits NF-kappaB and Wnt/beta-catenin signaling pathways via inactivation of Erk/MAPK and PI3K/Akt to induce intrinsic apoptosis in a hamster model of oral cancer. Biochim Biophys Acta. 2013; 1830(10): 4433-4444.

33. Li J, Dai W, Xia Y, et al. Astaxanthin inhibits proliferation and induces apoptosis of human hepatocellular carcinoma cells via inhibition of Nf-Kappab P65 and Wnt/Beta-Catenin in vitro. Mar Drugs. 2015; 13(10): 6064 6081. 
34. Chen JT, Kotani K. Astaxanthin as a potential protector of liver function: a review. J Clin Med Res. 2016; 8(10): 701-704.

35. Asrani SK, Devarbhavi H, Eaton J, Kamath PS. Burden of liver diseases in the world. J Hepatol. 2019; 70(1): $151-171$.

36. Mancuso A, Politi F, Maringhini A. Portal vein thromboses in cirrhosis: to treat or not to treat? Gastroenterology. 2018; 154(3): 758.

37. Tsuchida T, Friedman SL. Mechanisms of hepatic stellate cell activation. Nat Rev Gastroenterol Hepatol. 2017; 14(7): 397-411.

38. Yang Y, Bae M, Kim B, Park YK, Koo SI, Lee JY. Astaxanthin prevents and reverses the activation of mouse primary hepatic stellate cells. J Nutr Biochem. 2016; 29: 21-26.

39. Islam MA, Al Mamun MA, Faruk M, et al. Astaxanthin ameliorates hepatic damage and oxidative stress in carbon tetrachloride-administered rats. Pharmacognosy Res. 2017; 9(Suppl 1): S84-S91.

40. Yang Y, Kim B, Park YK, Koo SI, Lee JY. Astaxanthin prevents TGFbeta1-induced pro-fibrogenic gene expression by inhibiting Smad3 activation in hepatic stellate cells. Biochim Biophys Acta. 2015; 1850(1): 178-185.

41. Zhu S, Wang T, Luo F, et al. Astaxanthin inhibits proliferation and induces apoptosis of LX2 cells by regulating the miR29b/Bcl2 pathway. Mol Med Rep. 2019; 19(5): 3537-3547.

42. Shen M, Chen K, Lu J, et al. Protective effect of astaxanthin on liver fibrosis through modulation of TGF-beta1 expression and autophagy. Mediators Inflamm. 2014; 2014: 954502.

43. Hernandez-Gea V, Ghiassi-Nejad Z, Rozenfeld R, et al. Autophagy releases lipid that promotes fibrogenesis by activated hepatic stellate cells in mice and in human tissues. Gastroenterology. 2012; 142(4): 938-946.

44. Zhao Q, Qin CY, Zhao ZH, Fan YC, Wang K. Epigenetic modifications in hepatic stellate cells contribute to liver fibrosis. Tohoku J Exp Med. 2013; 229(1): 35-43.

45. Yang Y, Bae M, Park YK, et al. Histone deacetylase 9 plays a role in the antifibrogenic effect of astaxanthin in hepatic stellate cells. J Nutr Biochem. 2017; 40: 172-177.

46. Wu YJ, Wu YC, Chen IF, et al. Reparative effects of astaxanthin-hyaluronan nanoaggregates against retrorsine-CCl(4)-induced liver fibrosis and necrosis. Molecules. 2018; 23(4): 726.

47. Chiu CH, Chang CC, Lin ST, Chyau CC, Peng RY. Improved hepatoprotective effect of liposome-encapsulated astaxanthin in lipopolysaccharide-induced acute hepatotoxicity. Int J Mol Sci. 2016; 17(7): 1128.

48. Farrell GC, Wardell R, Teoh N, Chitturi S. Non-alcoholic fatty liver disease. Intern Med J. 2019; 49(5): 68168.

49. Sundelin EIO, Gormsen LC, Heeboll S, et al. Hepatic exposure of metformin in patients with non-alcoholic fatty liver disease. Br J Clin Pharmacol. 2019. 
50. Moore JB, Thorne JL. Predicting and reducing hepatic lipotoxicity in non-alcoholic fatty liver disease. Lab Anim (NY). 2019; 48(5): 143-144.

51. Ikeuchi M, Koyama T, Takahashi J, Yazawa K. Effects of astaxanthin in obese mice fed a high-fat diet. Biosci Biotechnol Biochem. 2007; 71(4): 893-899.

52. Ni Y, Nagashimada M, Zhuge F, et al. Astaxanthin prevents and reverses diet-induced insulin resistance and steatohepatitis in mice: a comparison with vitamin E. Sci Rep. 2015; 5(1): 17192.

53. Kim B, Farruggia C, Ku CS, et al. Astaxanthin inhibits inflammation and fibrosis in the liver and adipose tissue of mouse models of diet-induced obesity and nonalcoholic steatohepatitis. J Nutr Biochem. 2017; 43: 27-35.

54. Zheng $\mathrm{H}, \mathrm{Li} \mathrm{S}$, Ma L, et al. A novel agonist of PPAR-gamma based on barbituric acid alleviates the development of non-alcoholic fatty liver disease by regulating adipocytokine expression and preventing insulin resistance. Eur J Pharmacol. 2011; 659(2-3): 244-251.

55. Cao CY, Li YY, Zhou YJ, Nie YQ, Wan YJ. The C-681G polymorphism of the PPAR-gamma gene is associated with susceptibility to non-alcoholic fatty liver disease. Tohoku J Exp Med. 2012; 227(4): 253-262.

56. Kobori M, Takahashi Y, Sakurai M, et al. Hepatic transcriptome profiles of mice with diet-induced nonalcoholic steatohepatitis treated with astaxanthin and vitamin E. Int J Mol Sci. 2017; 18(3): 593.

57. Jia Y, Wu C, Kim J, Kim B, Lee SJ. Astaxanthin reduces hepatic lipid accumulations in high-fat-fed C57BL/6J mice via activation of peroxisome proliferator-activated receptor (PPAR) alpha and inhibition of PPAR gamma and Akt. J Nutr Biochem. 2016; 28: 9-18.

58. Yang JP, Shin JH, Seo SH, Kim SG, Lee SH, Shin EH. Effects of antioxidants in reducing accumulation of fat in hepatocyte. Int J Mol Sci. 2018; 19(9): 2563.

59. Xu J, Rong S, Gao H, et al. A combination of flaxseed oil and astaxanthin improves hepatic lipid accumulation and reduces oxidative stress in high fat-diet fed rats. Nutrients. 2017; 9(3): 271.

60. Yang Y, Pham TX, Wegner CJ, et al. Astaxanthin lowers plasma TAG concentrations and increases hepatic antioxidant gene expression in diet-induced obesity mice. Br J Nutr. 2014; 112(11): 1797-1804.

61. Yang Y, Seo JM, Nguyen A, et al. Astaxanthin-rich extract from the green alga Haematococcus pluvialis lowers plasma lipid concentrations and enhances antioxidant defense in apolipoprotein E knockout mice. $J$ Nutr. 2011; 141(9): 1611-1617.

62. Choi HD, Kim JH, Chang MJ, Kyu-Youn Y, Shin WG. Effects of astaxanthin on oxidative stress in overweight and obese adults. Phytother Res. 2011; 25(12): 1813-1818.

63. Tran KT, Coleman HG, McCain RS, Cardwell CR. Serum biomarkers of iron status and risk of primary liver cancer: a systematic review and meta-analysis. Nutr Cancer. 2019; 71: 1-9.

64. Golfieri R, Bargellini I, Spreafico C, Trevisani F. Patients with barcelona clinic liver cancer stages B and C hepatocellular carcinoma: time for a subclassification. Liver Cancer. 2019; 8(2): 78-91. doi:10.1159/00048979. 
65. Gradelet S, Astorg P, Le Bon AM, Berges R, Suschetet M. Modulation of aflatoxin B1 carcinogenicity, genotoxicity and metabolism in rat liver by dietary carotenoids: evidence for a protective effect of CYP1A inducers. Cancer Lett. 1997; 114(1-2): 221-223.

66. Tripathi DN, Jena GB. Astaxanthin intervention ameliorates cyclophosphamide-induced oxidative stress, DNA damage and early hepatocarcinogenesis in rat: role of Nrf2, p53, p38 and phase-II enzymes. Mutat Res. 2010; 696(1): 69-80.

67. Song X, Wang M, Zhang L, et al. Changes in cell ultrastructure and inhibition of JAK1/STAT3 signaling pathway in CBRH-7919 cells with astaxanthin. Toxicol Mech Methods. 2012; 22(9): 679-686.

68. Song XD, Zhang JJ, Wang MR, Liu WB, Gu XB, Lv CJ. Astaxanthin induces mitochondria-mediated apoptosis in rat hepatocellular carcinoma CBRH-7919 cells. Biol Pharm Bull. 2011; 34(6): 839-844.

69. Shao Y, Ni Y, Yang J, Lin X, Li J, Zhang L. Astaxanthin inhibits proliferation and induces apoptosis and cell cycle arrest of mice H22 hepatoma cells. Med Sci Monit. 2016; 22: 2152-2160.

70. Saxena NK, Fu PP, Nagalingam A, et al. Adiponectin modulates C-jun N-terminal kinase and mammalian target of rapamycin and inhibits hepatocellular carcinoma. Gastroenterology. 2010; 139(5): 1762-1773, 1773 e1761-1765.

71. Ohno T, Shimizu M, Shirakami Y, et al. Preventive effects of astaxanthin on diethylnitrosamine-induced liver tumorigenesis in C57/BL/KsJ-db/db obese mice. Hepatol Res. 2016; 46.

72. Rodriguez WE, Wahlang B, Wang Y, et al. PDE4 Inhibition as a therapeutic target for alcoholic liver disease: from bedside to bench. Hepatology. 2019; 70(6): 1958-1971. doi:10.1002/hep.30761

73. Braun HJ, Dodge JL, Grab JD, et al. Living donor liver transplant for alcoholic liver disease: data from the adult to adult living donor liver transplantation study (A2ALL). Transplantation. 2019.

74. Liu H, Liu H, Zhu L, et al. Comparative transcriptome analyses provide potential insights into the molecular mechanisms of astaxanthin in the protection against alcoholic liver disease in mice. Mar Drugs. 2019; 17(3): 181.

75. Han JH, Ju JH, Lee YS, et al. Astaxanthin alleviated ethanol-induced liver injury by inhibition of oxidative stress and inflammatory responses via blocking of STAT3 activity. Sci Rep. 2018; 8(1): 14090.

76. Liu H, Liu M, Fu X, et al. Astaxanthin prevents alcoholic fatty liver disease by modulating mouse gut microbiota. Nutrients. 2018; 10(9): 1298.

77. Wu YC, Huang HH, Wu YJ, Manousakas I, Yang CC, Kuo SM. Therapeutic and protective effects of liposomal encapsulation of astaxanthin in mice with alcoholic liver fibrosis. Int J Mol Sci. 2019; 20(16): 4057.

78. Turkez H, Geyikoglu F, Yousef MI. Beneficial effect of astaxanthin on 2,3,7,8-tetrachloro dibenzo-p-dioxin-induced liver injury in rats. Toxicol Ind Health. 2013; 29(7): 591-599.

79. Turkez H, Geyikoglu F, Yousef MI, et al. Hepatoprotective potential of astaxanthin against 2,3,7,8-tetrachloro dibenzo-p-dioxin in cultured rat hepatocytes. Toxicol Ind Health. 2014; 30(2): 101-112. 
80. Li J, Xia Y, Liu T, et al. Protective effects of astaxanthin on ConA-induced autoimmune hepatitis by the JNK/p-JNK pathway-mediated inhibition of autophagy and apoptosis. PLoS One. 2015; 10(3): e0120440.

81. Zhang J, Zhang S, Bi J, Gu J, Deng Y, Liu C. Astaxanthin pretreatment attenuates acetaminophen-induced liver injury in mice. Int Immunopharmacol. 2017; 45: 26-33.

82. Wei L, Chen WY, Hu T, et al. Effect and mechanism of propofol in hepatic ischemia/reperfusion injury of rat. Eur Rev Med Pharmacol Sci. 2017; 21(15): 3516-3522.

83. Li H, Xia Z, Chen Y, Qi D, Zheng H. Mechanism and therapies of oxidative stress-mediated cell death in ischemia reperfusion injury. Oxid Med Cell Longev. 2018; 2910643.

84. Yucel A, Aydogan MS, Ucar M, Sarici KB, Karaaslan MG. Effects of apocynin on liver ischemia-reperfusion injury in rats. Transplant Proc. 2019; 51(4): 1180-1183.

85. Xue Y, Qu Z, Fu J, et al. The protective effect of astaxanthin on learning and memory deficits and oxidative stress in a mouse model of repeated cerebral ischemia/reperfusion. Brain Res Bull. 2017; 131: 221-228.

86. Pongkan W, Takatori $\mathrm{O}, \mathrm{Ni} \mathrm{Y}$, et al. beta-Cryptoxanthin exerts greater cardioprotective effects on cardiac ischemia-reperfusion injury than astaxanthin by attenuating mitochondrial dysfunction in mice. Mol Nutr Food Res. 2017; 61(10): 1601077.

87. Otsuka T, Shimazawa M, Inoue Y, et al. Astaxanthin protects against retinal damage: evidence from in vivo and in vitro retinal ischemia and reperfusion models. Curr Eye Res. 2016; 41(11): 1465-1472.

88. Curek GD, Cort A, Yucel G, et al. Effect of astaxanthin on hepatocellular injury following ischemia/reperfusion. Toxicology. 2010; 267(1-3): 147-153.

89. Li J, Wang F, Xia Y, et al. Astaxanthin pretreatment attenuates hepatic ischemia reperfusion-induced apoptosis and autophagy via the ROS/MAPK pathway in mice. Mar Drugs. 2015; 13(6): 3368-3387.

90. Li S, Takahara T, Fujino M, et al. Astaxanthin prevents ischemia-reperfusion injury of the steatotic liver in mice. PLoS One. 2017; 12(11): e0187810.

91. Bhuvaneswari S, Anuradha CV. Astaxanthin prevents loss of insulin signaling and improves glucose metabolism in liver of insulin resistant mice. Can J Physiol Pharmacol. 2012; 90(11): 1544-1552. 